\title{
CORRELAÇÃO ENTRE DIGESTIBILIDADE DOS NUTRIENTES E O COMPORTAMENTO INGESTIVO DE NOVILHOS EM PASTEJO
}

\author{
CORRELATION BETWEEN NUTRIENT DIGESTIBILITY AND INGESTIVE BEHAVIOR IN \\ CROSSBRED STEERS RECREATED AT PASTURES
}

\author{
Dias, D.L.S. ${ }^{1}$; Silva, R.R. ${ }^{1}$; Silva, F.F. ${ }^{1}$; Carvalho, G.G.P.'; Brandão, R.K.C. ${ }^{1}$; Souza, S.O.. \\ Guimarães, J. de O. ${ }^{1}$; Pereira, M.M.S. ${ }^{1}$ e Costa, L.S ${ }^{1}$.
}

${ }^{1}$ Universidade Estadual do Sudoeste da Bahia. Campus de Itapetinga. Itapetinga. Bahia. Brasil. *dlsd_@hotmail.com

2Universidade Federal da Bahia. UFBA. Salvador. Bahia. Brasil.

\section{PalaVRas ChaVE ADICIONAIS}

Digestão. Eficiencia de ruminação. Mastigação. Suplementação mineral.

\section{RESUMO}

Objetivou-se com esse estudo avaliar as correlações existentes entre o consumo de nutrientes e o comportamento ingestivo de novilhos mestiços $1 / 2$ Holandês $x$ Zebu na fase de recria em pastagem de Brachiaria brizantha 'Marandu', no período das águas. Foram utilizados 22 novilhos com média de sete meses de idade e peso corporal médio inicial de $164,09 \pm 12,13 \mathrm{~kg}$, distribuídos em delineamento inteiramente casualizado, com dois tipos de suplemento e onze repetições por tipo de suplementação e manejados em pastejo rotacionado numa área de 6,5 ha. Efetuou-se a análise de correlação linear de Pearson entre as variáveis comportamentais estudadas e os coeficientes de digestibilidade dos nutrientes encontrados. Os coeficientes de correlação foram testados por meio do teste $t$. O tempo de ruminação apresentou correlação positiva com o coeficiente de digestibilidade dos nutrientes. O tempo de alimentação no cocho correlacionou positivamente com o coeficiente de digestibilidade da matéria seca (MS), matéria orgânica (MO), proteína bruta (PB) e extrato etéreo (EE). Correlação positiva foi observada entre o tempo de mastigação total e o coeficiente de digestibilidade dos nutrientes. O número de períodos de ócio e ruminação apresentaram correlações positivas com o coeficiente de digestibilidade dos nutrientes e o numero de períodos de alimentação no cocho correlacionou positivamente com o coeficiente de digestibilidade da PB. A taxa de bocados e o número de bocados

\section{AdDITIONAL KEYWORDS}

Digestion. Efficiency of rumination. Chewing. Mineral supplementation.

por dia correlacionaram-se positivamente com o coeficiente de digestibilidade dos nutrientes. Correlação positiva foi observada entre o número de mastigações merícicas por dia e o coeficiente de digestibilidade da MS, MO e carboidratos totais (CT). Correlações positivas foram observadas entre as eficiências de alimentação e ruminação da matéria seca e da fibra em detergente neutro com o coeficiente de digestibilidade dos nutrientes estudados. A digestibilidade dos nutrientes exerce influência direta sobre as expressões comportamentais apresentadas pelos animais estudados.

\section{SUMMARY}

The objective of this study was to evaluate the correlations between nutrient intake and ingestive behavior of steers Holstein $\times$ Zebu in the rearing on Brachiaria brizantha 'Marandu', during the rainy season. We used 22 steers averaging seven months of age and mean initial body weight of $164,09 \pm 12,13$ $\mathrm{kg}$, distributed in a completely randomized design with two types of supplement and eleven repetitions per supplementation and managed in a rotational grazing area of 6,5 ha Pearson linear correlations between the behavioral variables and the digestibility of the nutrients were studied. The correlation coefficients were tested by the $t$ test. The rumination time was positively correlated with the digestibility of nutrients. Feeding time at the trough positively 
correlated with the digestibility of dry matter (DM), organic matter (ODM), crude protein (CP) and ether extract. Positive correlation was observed between total chewing time and digestibility of nutrients. The number of periods of idle and rumination showed positive correlations with the digestibility of nutrients and the number of feeding periods in the trough correlated positively with the digestibility coeficient of CP. Bite rate and the number of bites per day correlated positively with the digestibility of nutrients. Positive correlation was observed between the number of chews per day and digestibility of DM, OM and total carbohydrates (CT). Positive correlations were observed between the efficiencies of feeding and rumination of dry matter and neutral detergent fiber with digestibility coefficient of nutrients studied. The nutrient digestibility has a direct influence over the behavioral expressions of animals studied.

\section{INTRODUÇÃO}

Um dos principais fatores que associado ao desempenho animal é o consumo de nutrientes, porem além do conhecimento do consumo e da composição química dos alimentos, torna-se importante o conhecimento da utilização dos nutrientes pelo animal, que é obtido por meio de estudos de digestão, (Silva et al., 2010). Compreender a expressão dos fenômenos biológicos por meio do estudo do comportamento animal é um grande desafio para os pesquisadores da área de etologia. De acordo com Coelho da Silva e Leão (1979), a digestibilidade é característica do alimento e indica a porcentagem de cada nutriente de um alimento que o animal pode utilizar.

É sabido também que existe influência do animal na digestibilidade dos alimentos. Assim sendo, por ser uma característica influenciada tanto pelo animal como pelo alimento, fatores como o manejo da alimentação e o ambiente podem afetar a digestibilidade de determinado alimento e essa influência ser expressa em seu comportamento alimentar.

Há uma escassez de pesquisas que relatam as correlações existentes entre o consumo de nutrientes e o comportamento ingestivo de animais em pastejo, o que justificaria a intensificação e aprofundamento dos estudos nesta área do conhecimento que é tão importante e gera informações de extrema relevância para a produção de bovinos em pastejo.

Objetivou-se avaliar as correlações entre a digestibilidade dos nutrientes e o comportamento ingestivo em novilhos mestiços recriados em pastagens no período das águas.

\section{MATERIAL E MÉTODOS}

O experimento foi desenvolvido na fazenda Princesa do Mateiro, município de Ribeirão do Largo, localizado na região sudoeste do estado da Bahia. Foram utilizados 22 novilhos mestiços não castrados $1 / 2$ Holandes-Zebu, com média de sete meses de idade e peso corporal médio inicial de $164,09 \pm 12,13 \mathrm{~kg}$. O período experimental compreendeu de 27 de novembro de 2011 a 04 de março de 2012, (98 dias), sendo 14 deles destinados a adaptação dos animais ao manejo e a dieta experimental.

Os animais foram mantidos em pastejo rotacionado de Brachiaria brizantha 'Marandú', em área total de 6,5 ha, sendo esta dividida em seis piquetes de áreas equivalentes.

Os animais foram identificados por meio de suas características morfológicas e brincos plásticos numerados, pesados e alocados ao tipo de suplementação por meio do delineamento inteiramente casualizado. Cada tipo de suplementação possuía 11 repetições e consistia em:

Tabela I. Ingredientes do suplemento proteico/ energético. (Ingredients of supplement).

\begin{tabular}{lc}
\hline Ingrediente (\%) & $\%$ \\
\hline Milho & 45,4398 \\
Farelo de soja & 45,4398 \\
${\text { Ureia }+ \text { SA }^{1}}_{\text {Mistura mineral }^{2}}^{4,9928}$ \\
\hline
\end{tabular}

${ }^{1}$ Ureia + Sulfato de amônio (9:1); ${ }^{2}$ Composição: Cálcio 235 g; Fósforo 160 g; Magnésio 16 g; Enxofre $12 \mathrm{~g}$; Cobalto $150 \mathrm{mg}$; Cobre $1600 \mathrm{mg}$; lodo $190 \mathrm{mg}$; Manganês $1400 \mathrm{mg}$; Ferro 1000 mg; Selênio $32 \mathrm{mg}$; Zinco 6000 mg; 1120 mg; Flúor (máximo) 1600 mg. 


\section{CORRELAÇÃO ENTRE DIGESTIBILIDADE DOS NUTRIENTES E O COMPORTAMENTO}

Suplementação proteico/energético $0,4 \%$ do peso corporal em suplemento por dia, balanceado para suprir as exigências em nutrientes para ganho de $1 \mathrm{~kg} / \mathrm{dia}$ (NRC, 2001). Suplementação mineral-suplemento mineral ad libitum. A suplementação foi fornecida diariamente às 10:00 horas, em cochos plásticos.

A estimativa da produção fecal, consumo e digestibilidade foram realizadas entre os dias 14 a 21 de janeiro de 2012, datas estas compreendidas na metade do período experimental total.

Para estimar a produção fecal utilizou-se o LIPE ${ }^{\circledR}$, (lignina purificada e enriquecida), como indicador externo, fornecido diariamente às sete horas da manhã, uma cápsula em dose única por animal com 7 dias para adaptação e regulação do fluxo de excreção do marcador e cinco dias para coleta das fezes.

As fezes foram coletadas uma vez ao dia, durante cinco dias, no próprio piquete em cinco horários pré-estabelecidos. Posteriormente as fezes foram armazenadas em câmara fria a $-10{ }^{\circ} \mathrm{C}$. As amostras de fezes coletadas foram pré-secas e moídas em moinho de faca (peneira com crivos de $1 \mathrm{~mm}$ ), para as posteriores análises em laboratório. A estimativa da produção fecal foi feita determinando o teor de LIPE ${ }^{\circledR}$ nas fezes, utilizando a metodologia proposto por (Saliba et al., 2003).

$\mathrm{O}$ consumo de MS de concentrado foi estimado com a utilização do indicador dióxido de titânio $\left(\mathrm{TiO}_{2}\right)$, o qual foi fornecido na quantidade de $10 \mathrm{~g}$ por animal, misturado ao concentrado, durante oito dias, utilizando procedimento descrito por Valadares Filho et al. (2006), seguindo o mesmo esquema de coleta de fezes descrito para estimar a produção fecal, através da equação: $\mathrm{CMSS}=(\mathrm{EFxTiO}$ fezes) / TiO suplemento, em que: TiO fezes e TiO suplemento referem-se à concentração de dióxido de titânio nas fezes e suplemento, respectivamente.

Adeterminação da concentração de titânio foi feito segundo metodologia de Detmann et al. (2012). O consumo individual de concentrado foi estimado dividindo-se a excreção total de $\mathrm{TiO}_{2}$ pela sua respectiva concentração no concentrado.

Para estimativa do consumo voluntário de volumoso foi utilizado o indicador interno FDN indigestível (FDNi), obtido após incubação ruminal por 240 horas (Casali, 2006), de $0,5 \mathrm{~g}$ de amostras de alimentos, sobras e fezes em duplicata, utilizando sacos confeccionados com tecido não tecido (TNT) gramatura 100 $\left(100\right.$ g. $\left.\mathrm{m}^{2}\right), 5 \times 5 \mathrm{~cm}$. O material remanescente da incubação foi submetido à extração com detergente neutro, para determinação da FDNi.

O consumo de MS foi calculado da seguinte forma:

CMS total $(\mathrm{kg} / \mathrm{dia})=[(\mathrm{EFXCIF})-\mathrm{IS}]+\mathrm{CMSS} / \mathrm{CIV}$, em que:

$E F=$ excreção fecal (kg/dia), obtida utilizando-se o dióxido de titânio,

$\mathrm{CIF}=$ concentração do indicador nas fezes $(\mathrm{kg} / \mathrm{kg})$,

$\mathrm{CIV}=$ concentração do indicador no volumoso $(\mathrm{kg} /$ $\mathrm{kg}$ ),

IS= quantidade do indicador presente no concentrado,

CMSS = consumo de MS do concentrado.

As amostras da forragem do pastejo simulado foram obtidas através do consumo observado dos animais experimentais, conforme Johnson (1978), identificando-se o tipo de material consumido e coletando-se uma amostra semelhante ao alimento ingerido.

As amostras de concentrado, forragem e fezes, após a pré-secagem foram moídas em moinho tipo Willey a $1 \mathrm{~mm}$ para a realização das análises químicas.

Os teores de matéria seca (MS), proteína bruta $(\mathrm{PB})$, extrato etéreo (EE), fibra em detergente ácido (FDA) e cinza, que foram obtidas conforme metodologias descritas por AOAC (1990). O teor de FDN, corrigido para cinzas e proteínas, foi realizado segundo recomendações de Mertens (2002), tabela II.

Os carboidratos não fibrosos corrigidos para cinzas e proteína (CNFcp) foram obtidos por meio da equação (Hall, 2003): 
Tabela II. Composição química da Brachiaria brizantha $(B b)$ e da suplementação proteico/ energetica (Spe). (Chemical composition of Brachiaria Brizantha $(\mathrm{Bb})$ and of protein/energy supplementation (Spe)).

\begin{tabular}{lcc}
\hline Composição química & $B b^{1}$ & Spe \\
\hline Matéria seca & 24,81 & 87,06 \\
Matéria mineral & 7,89 & 10,24 \\
Proteína bruta & 12,20 & 48,21 \\
Extrato etéreo & 2,16 & 2,72 \\
FDA $^{2}$ & 35,84 & 8,77 \\
FDNcp $^{3}$ & 67,52 & 31,74 \\
CNF & 10,22 & 15,84 \\
CT & 77,74 & 38,82 \\
NDT $^{4}$ & 53,09 & 60,00 \\
\hline
\end{tabular}

${ }^{1}$ Pastejo simulado; ${ }^{2} \mathrm{FDA}=$ fibra em detergente ácido; ${ }^{3} \mathrm{FDNcp}=$ fibra em detergente neutro corrigido para cinzas e proteína; ${ }^{4} \mathrm{NDT}=$ Nutrientes digestíveis totais, $\mathrm{CNF}=$ Carboidratos não fibrosos e CT= Carboidratos totais.

$\mathrm{CNF} c \mathrm{c}=100-[(\% \mathrm{~PB}-\% \mathrm{~PB}$ da ureia $+\%$ ureia $)+$ FDNcp $+\% E E+\%$ Cinzas] .

Os carboidratos totais (CT), por meio da equação (Sniffen et al., 1992):

$100-(\% P B+\% E E+\%$ Cinzas $)$.

Os nutrientes digestíveis totais (NDT), pela equação de Weiss (1999), mas utilizando a FDN corrigida paro para cinzas e proteína:

NDT= \%PB digestível + \%FDNcp digestível + \%CNF digestível $+(2,25$ * \%EE digestível) .

As avaliações do comportamento ingestivo foram realizadas no $34^{\circ}$ e $41^{\circ}$ dia de experimento, no mês de Janeiro de 2012, sendo realizadas observações a cada 5 minutos, conforme metodologia de Silva et al. (2006), por um período de 24 horas.

Os animais foram avaliados visualmente, por dois observadores treinados para cada tipo de suplemento com auxílio de binóculos, sendo os mesmos, posicionados estrategicamente de forma a não influenciar o comportamento animal. Para obter o tempo gasto em cada atividade, foram utilizados relógios digitais e para o período de avaliação noturna os observadores utilizaram lanternas para o auxilio na coleta dos dados.

As variáveis comportamentais observadas compreenderam ao tempo de pastejo, tempo de ruminação, tempo de ócio e tempo de alimentação no cocho. A partir dos dados coletados, efetuou-se a tabulação e os cálculos, sendo que os tempos de alimentação e ruminação ainda foram calculados em função do consumo de MS e FDN ( $\mathrm{min} / \mathrm{kg}$ MS ou FDN).

O tempo de alimentação total (TAT) e de mastigação total (TMT) foi determinado pelas equações:

TAT = tempo de pastejo + tempo de alimentação no cocho;

TMT = tempo de pastejo + tempo de ruminação + tempo de alimentação no cocho.

Foi colocado um observador treinado especificamente para a obtenção do número de mastigações merícicas e do tempo despendido na ruminação de cada bolo ruminal, para cada animal, feitas através das observações de três bolos ruminais em três períodos diferentes do dia (09-12, 15-18 e 19-21 horas), segundo (Burger et al., 2000). Para obtenção do número de bolos diários, procedeu-se à divisão do tempo total de ruminação pelo tempo médio gasto na ruminação de cada bolo, descrito anteriormente.

A discretização das séries temporais foi feita diretamente nas planilhas de coleta de dados, com a contagem dos períodos discretos de pastejo, ruminação, ócio e alimentação no cocho. A duração média de cada um dos períodos discretos foi obtida pela divisão dos tempos diários de cada uma das atividades pelo número de períodos discretos da mesma atividade, conforme descrito por Silva et al. (2006). 
As MS e FDN/refeição foram obtidas dividindo-se o consumo médio individual de cada fração pelo número de períodos de alimentação por dia (em 24 horas). A eficiência de alimentação e ruminação, expressa em g MS/hora e g FDN/hora, foi obtida pela divisão do consumo médio diário de MS e FDN pelo tempo total despendido em alimentação e/ou ruminação em 24 horas, respectivamente. As variáveis g de MS e FDN/bolo foram obtidas dividindo-se o consumo médio individual de cada fração pelo número de bolos ruminados por dia (em 24 horas).

A taxa de bocado (TxBOC) dos animais de cada tipo de suplementação foi estimada por meio do tempo gasto pelo animal para realizar 20 bocados (Hodgson, 1982). Para o cálculo da massa de bocado (MasBOC), dividiu-se o consumo diário pelo total de bocados diários (Jamieson e Hodgson, 1979). Os resultados das observações de bocados e deglutição foram registrados em seis ocasiões durante o dia, conforme Baggio et al. (2009), sendo três avaliações durante a manhã e três à tarde, e usados também para determinar o número de bocados por dia (BOCDIA), que é o produto entre taxa de bocado e tempo de pastejo.

Os dados de digestibilidade dos nutrientes e comportamento foram correlacionados utilizando-se a correlação Lienar de Pearson. Os coeficientes de correlação foram testados por meio do teste $t$ e processadas pelo Sistema de Análises Estatísticas e Genéticas - SAEG (2001), sendo consideradas significativas quando $\mathrm{p}<0,05$. Utilizaram-se os seguintes parâmetros: digestibilidade dos nutrientes e comportamento ingestivo, tabelas III e IV, respectivamente.

Os coeficientes de correlação não significativos não foram apresentados nas tabelas.

\section{RESULTADOS E DISCUSSÃO}

Não foi verificado nenhum tipo de correlação entre o tempo de pastejo (PAS) e o tempo de alimentação total (TAT) com os coeficientes de digestibilidades estudados $(p>0,05)$ (tabela V). Diferentemente dos
Tabela III. Coeficientes de digestibilidade (\%) dos nutrientes em novilhos mestiços recebendo suplementação proteico/energética (Spe) ou suplementação mineral (Sm) em pastagens de Brachiaria brizantha 'Marandu'no periodo das águas. (Digestibility coefficients (Spe) of nutrients in crossbred steers receiving protein/energy supplementation (Spe) or mineral supplementation (Sm) in pasture Brachiaria brizantha 'Marandu' during the rainy season).

\begin{tabular}{lcc}
\hline & Spe & Sm \\
\hline CDMS & 62,04 & 53,88 \\
CDMO & 64,54 & 56,65 \\
CDFDNcp & 64,46 & 59,26 \\
CDPB & 62,97 & 40,00 \\
CDEE & 79,40 & 71,11 \\
CDCNF & 65,09 & 52,48 \\
CDCT & 64,49 & 58,91 \\
\hline
\end{tabular}

CDMS $=$ Coeficiente de digestibilidade da matéria

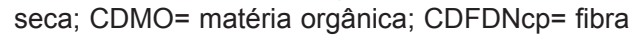
em detergente neutro corrigido para cinzas e proteína; $C D P B=$ proteína bruta; $C D E E=$ extrato etéreo; $\mathrm{CDCNF}=$ carboidratos não fibrosos e $\mathrm{CDCT}=$ carboidratos totais.

resultados aqui obtidos, Santana Junior et al. (2012) observaram correlação positiva entre o tempo de pastejo e a digestibilidade da FDN, sendo justificado pelos autores pela taxa de passagem do volumoso onde o limitante é o efeito de enchimento provocado pela FDN em animais em pastagens tropicais, pois quanto maior a digestibilidade da FDN, menor tempo a mesma ficará no rúmen, propiciando assim, maior oportunidade de pastejo do animal.

O tempo de ócio (ÓCIO) se correlacionou negativamente $(\mathrm{p}<0,05)$ com o coeficiente de digestibilidade dos nutrientes. Os animais que recebiam suplementação proteico/energética tiveram maior digestibilidade da MS assim como dos demais nutrientes o que está diretamente relacionado com a melhoria do ambiente ruminal devido ao maior aporte de nutrientes à população microbiana. Segundo Lazzarini et al. (2009) o fornecimento de suplementação mostra-se eficiente, pois oferece 
Tabela IV. Valores médios do comportamento ingestivo, aspectos do bocado, aspectos da ruminação, períodos discretos e eficiências de alimentação e ruminação de novilhos mestiços recebendo suplementação proteica/energética ou suplementação mineral em pastagens de Brachiaria brizantha 'Marandu' no período das águas. (Mean values of ingestive behavior aspects bit, aspects of rumination, discrete periods and efficiencies of feeding and rumination of crossbred steers receiving supplementation of protein/energy or mineral supplementation grazing Brachiaria brizantha 'Marandu' during the rainy season).

\begin{tabular}{|c|c|c|}
\hline \multirow{2}{*}{ Item (\%) } & \multicolumn{2}{|c|}{ Suplementação } \\
\hline & Proteico/energética & Mineral \\
\hline Pastejo (min) & 457,04 & 442,95 \\
\hline Ócio (min) & 490,00 & 558,86 \\
\hline Ruminação (min) & 466,59 & 423,63 \\
\hline Alimentação no cocho (min) & 26,36 & 14,54 \\
\hline Mastigação total (min) & 950,00 & 881,14 \\
\hline Alimentação total (min) & 483,41 & 457,50 \\
\hline TxBOC (n\%seg) & 0,81 & 0,64 \\
\hline MasBOC (g MS) & 0,34 & 0,37 \\
\hline NumBOC ( $\mathrm{n} /$ deglutido) & 24,86 & 21,60 \\
\hline TemBOC (tempo/deglutido) & 31,54 & 34,32 \\
\hline BOCDIA (n\%dia) & 22216,96 & 16990,22 \\
\hline Bolos/dia & 627,69 & 572,72 \\
\hline Tempo/bolo (seg) & 45,17 & 44,53 \\
\hline Mastigações/bolo & 53,25 & 52,04 \\
\hline Mastigações/dia & 33240,98 & 29699,84 \\
\hline NPP & 13,09 & 12,09 \\
\hline NPO & 30,45 & 23,45 \\
\hline NPR & 21,91 & 16,54 \\
\hline NPC & 3,00 & $1,82 b$ \\
\hline TPP (min) & 32,79 & 36,95 \\
\hline TPO (min) & 14,94 & 17,35 \\
\hline TPR (min) & 26,46 & 37,79 \\
\hline TPC (min) & 8,20 & 7,00 \\
\hline INGMS (g MS/refeição) & 455,51 & 534,73 \\
\hline INGFDN (g FDNcp/refeição) & 285,06 & 358,27 \\
\hline EALMS (kg MS/hora) & 100,80 & 105,86 \\
\hline EALFDN (kg FDNcp/hora) & 122,45 & 149,92 \\
\hline ERUMS (kg MS/hora) & 0,90 & 0,60 \\
\hline ERUFDN (kg FDN/hora) & 0,50 & 0,40 \\
\hline RUGMS (g de MS/bolo) & 12,01 & 11,36 \\
\hline RUGFDN (g de FDN/bolo) & 7,52 & 7,60 \\
\hline
\end{tabular}

condições para que os microrganismos utilizem eficientemente os carboidratos fibrosos presentes na dieta basal, a forragem. Portanto, houve melhoria na digestibilidade do material 


\section{CORRELAÇÃO ENTRE DIGESTIBILIDADE DOS NUTRIENTES E O COMPORTAMENTO}

ingerido, graças ao suprimento dos fatores nutricionais para os microrganismos ruminais.

O tempo de ruminação apresentou correlação positiva $(p<0,05)$ com o coeficiente de digestibilidade dos nutrientes. O tempo de ruminação é altamente correlacionado $(\mathrm{r}=0,96)$ com o consumo de FDN em bovinos (Mendonça et al., 2004). O processo de ruminação favorece o melhor aproveitamento dos constituintes da dieta por meio do tamponamento do rúmen, bem como da redução do tamanho das partículas do alimento. Sendo assim, a digestibilidade é favorecida quando ocorre um aumento do tempo de ruminação. Durante a época das aguas, onde ocorre à melhoria do valor nutricional das pastagens, o fornecimento de suplemento aos animais melhora a utilização dos nutrientes no rúmen, por possibilitar a sincronia entre proteína e energia (Souza et al. 2012), melhorando a digestibilidade dos nutrientes.

O tempo de alimentação no cocho correlacionou positivamente $(\mathrm{p}<0,05)$ com o CDMS, CDMO, CDPB e CDEE. Vários relatos da literatura versaram indiretamente sobre o tema sem, no entanto quantificar por meio de algum teste as relações existentes entre a digestão dos nutrientes e a expressão dessas inter-relações via comportamento animal. Segundo Rode et al. (1985), os valores de digestibilidade da MS e MO elevaram-se à medida adiciona-se o concentrado na dieta em virtude da redução de carboidratos estruturais e do aumento no teor de carboidratos não-estruturais na dieta. $\mathrm{O}$ aumento nos consumos de $\mathrm{PB}$ e EE graças ao aporte adicional destes nutrientes na dieta proporcionou aumento no coeficiente de digestibilidade dos mesmos. Neste prisma, o aporte adicional desses nutrientes via suplementação auxiliou na melhoria da digestibilidade, taxa de passagem e consequentemente o consumo desses nutrientes pelos animais.

A correlação positiva $(\mathrm{p}<0,05)$ existente entre o tempo de mastigação total e o coeficiente de digestibilidade dos nutrientes, provavelmente, se deu por conta do tempo de ruminação que quando se eleva, proporciona melhorias na digestibilidade dos nutrientes.

O NPO e NPR apresentaram correlações positivas $(\mathrm{p}<0,05)$ com o coeficiente de diges-

Tabela $\boldsymbol{V}$. Coeficientes de correlação linear entre a digestibilidade dos nutrientes e o comportamento ingestivo de novilhos mestiços recebendo suplementação proteico/energética ou suplementação mineral em pastagens de Brachiaria brizantha 'Marandu' no periodo das águas. (Linear correlation coefficients between nutrient digestibility and feeding behavior of crossbred steers receiving protein / energy supplementation or mineral supplementation on Brachiaria brizantha 'Marandu' during rainy).

\begin{tabular}{lcccccc}
\hline Variável & PAS & ÓCIO & RUM & COC & TMT & TAT \\
\hline CDMS & - & $-0,4218$ & 0,4131 & 0,3619 & 0,4203 & - \\
CDMO & - & $-0,4122$ & 0,4179 & 0,3681 & 0,4106 & - \\
CDFDNcp & - & $-0,3678$ & 0,4062 & - & 0,3662 & - \\
CDPB & - & $-0,4319$ & 0,3867 & 0,5089 & 0,4309 & - \\
CDEE & - & -0.5038 & 0,4693 & 0,4440 & 0,5029 & - \\
CDCNF & - & $-0,3807$ & 0,3756 & - & 0,3786 & - \\
CDCT & - & $-0,3801$ & 0,4128 & - & 0,3782 & - \\
\hline
\end{tabular}

$\mathrm{PAS}=$ tempo de pastejo; $\mathrm{O} C I O=$ tempo de ócio; $\mathrm{RUM}=$ tempo de ruminação; $\mathrm{COC}=$ tempo de cocho; TMT= tempo de mastigação total; TAT= tempo de alimentação total; $C D M S=$ coeficiente de digestibilidade da matéria seca; $\mathrm{CDMO}=$ coeficiente de digestibilidade da matéria orgânica; $C D F D N c p=$ coeficiente de digestibilidade da fibra em detergente neutro corrigido para cinzas e proteína; $C D P B=$ coeficiente de digestibilidade da proteína bruta; $\mathrm{CDEE}=$ coeficiente de digestibilidade do extrato etéreo; $\mathrm{CDCNF}=$ coeficiente de digestibilidade do carboidrato não fibroso; $C D C T=$ coeficiente de digestibilidade dos carboidratos totais. 
tibilidade dos nutrientes (tabela VI). Para um melhor aproveitamento do material ingerido é necessário maior tempo de ruminação, pois segundo Van Soest (1994), a digestibilidade pode ser definida como um processo de conversão de macromoléculas dos nutrientes em compostos mais simples, que podem ser absorvidos no trato gastrintestinal. Ao consumirem alimentos mais concentrados e se saciarem em menor tempo de alimentação, os animais também necessitam de menor tempo de ruminação. Assim sendo, ficam por mais períodos em ócio. A digestibilidade dos alimentos concentrados é superior à das forragens. O NPC correlacionou positivamente $(\mathrm{p}<0,05)$ com o CDPB. Como é de conhecimento geral, o aumento no consumo de determinado nutriente inserido em um suplemento concentrado leva a um aumento na digestibilidade do mesmo. Quando animais são suplementados em pastejo pode existir uma melhoria na condição ruminal para degradação dos nutrientes, visto que a maior disponibilidade de $\mathrm{N}$ pode pro- piciar o crescimento da microbiota ruminal e consequentemente favorecer a digestibilidade.

O TPR apresentou correlação negativa $(p<0,05)$ com o coeficiente de digestibilidade dos nutrientes estudados. Por ser fruto da divisão do tempo total de ruminação pelo NPR, a correlação mostra-se coerente, pois, quanto maior for o número de períodos, menor será o tempo por cada período. Sendo assim, em decorrência do comportamento apresentado pelo NPR refletiu no TPR, que apresentou correlação negativa $(p<0,05)$ com o coeficiente de digestibilidade dos nutrientes.

A taxa de bocados (TxBOC) e o número de bocados por dia (BOCDIA) correlacionaramse positivamente $(p<0,05)$ com o coeficiente de digestibilidade de todos os nutrientes estudados (tabela VII). Estas variáveis dependem de características inerentes à oferta de forragem, estrutura do dossel forrageiro podendo conduzir à uma maior facilidade ou dificuldade com que o animal apreende a forragem (Trevisan et al., 2004). Como

Tabela VI. Coeficientes de correlação linear entre a digestibilidade dos nutrientes e os períodos discretos do comportamento ingestivo de novilhos mestiços recebendo suplementação proteico/ energética ou suplementação mineral em pastagens de Brachiaria brizantha 'Marandu' no período das águas. (Linear correlation coefficients between nutrient digestibility and discrete periods of feeding behavior of crossbred steers receiving supplemental protein / energy or mineral supplementation on Brachiaria brizantha cv. Marandu during rainy).

\begin{tabular}{lcccccccc}
\hline & NPP & NPO & NPR & NPC & TPP & TPO & TPR & TPC \\
\hline CDMS & - & 0,4844 & 0,4930 & - & - & - & $-0,4508$ & - \\
CDMO & - & 0,4709 & 0,4923 & - & - & - & $-0,4496$ & - \\
CDFDNcP & - & 0,3323 & 0,3969 & - & - & - & $-0,3726$ & - \\
CDPB & - & 0,6134 & 0,5841 & 0,4127 & - & - & $-0,5354$ & - \\
CDEE & - & 0,5951 & 0,6406 & - & - & - & $-0,6190$ & - \\
CDCNF & - & 0,4737 & 0,4363 & - & - & - & $-0,3761$ & - \\
CDCT & - & 0,3706 & 0,4144 & - & - & - & $-0,3780$ & - \\
\hline
\end{tabular}

${ }^{1} \mathrm{NPP}=$ número de períodos de pastejo; $\mathrm{NPO}=$ número de períodos de ócio; NPR= número de períodos de ruminação; NPC= número de períodos de alimentação no cocho; TPP= tempo por período de pastejo; $\mathrm{TPO}=$ tempo por período de ócio; TPR= tempo por período de ruminação; TPC= tempo por período de alimentação no cocho; CDMS= coeficiente de digestibilidade da matéria seca; $\mathrm{CDMO}=$ coeficiente de digestibilidade da matéria orgânica; $\mathrm{CDFDNcp}=$ coeficiente de digestibilidade da fibra em detergente neutro corrigido para cinzas e proteína; $\mathrm{CDPB}=$ coeficiente de digestibilidade da proteína bruta; $\mathrm{CDEE}=\mathrm{Coeficiente}$ de digestibilidade do extrato etéreo; $\mathrm{CDCNF}=$ coeficiente de digestibilidade do carboidrato não fibroso; $\mathrm{CDCT}=$ coeficiente de digestibilidade dos carboidratos totais. 
Tabela VII. Coeficientes de correlação linear entre a digestibilidade dos nutrientes e os aspectos do bocado do comportamento ingestivo de novilhos mestiços recebendo suplementação proteico/energética ou suplementação mineral em pastagens de Brachiaria brizantha 'Marandu' no período das águas. (Linear correlation coefficients between nutrient digestibility and aspects of bit feeding behavior of crossbred steers receiving protein / energy supplementation or mineral supplementation on Brachiaria brizantha 'Marandu' during rainy).

\begin{tabular}{lccccc}
\hline & TxBOC & MasBOC & NumBOC & TemBOC & BOCDIA \\
\hline CDMS & 0,5387 & - & - & - & 0,4925 \\
CDMO & 0,5504 & - & - & - & 0,4882 \\
CDFDNcp & 0,4325 & - & - & - & 0,3543 \\
CDPB & 0,7026 & - & 0,4162 & - & 0,6429 \\
CDEE & 0,8022 & - & - & $-0,5158$ & 0,7275 \\
CDCNF & 0,4707 & - & - & - & 0,4534 \\
CDCT & 0,4333 & - & - & - & 0,3737 \\
\hline
\end{tabular}

${ }^{1} \mathrm{~T} \times \mathrm{BOC}=$ taxa de bocado; $\mathrm{MasBOC}=$ massa de bocado; NumBOC= número de bocados por deglutição;

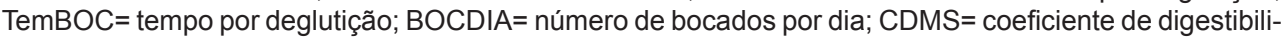
dade da matéria seca; $\mathrm{CDMO}=$ coeficiente de digestibilidade da matéria orgânica; $C D F D N c p=$ coeficiente de digestibilidade da fibra em detergente neutro corrigido para cinzas e proteína; $C D P B=$ coeficiente de digestibilidade da proteína bruta; $\mathrm{CDEE}=$ coeficiente de digestibilidade do extrato etéreo; $\mathrm{CDCNF}=$ coeficiente de digestibilidade do carboidrato não fibroso; $C D C T=$ coeficiente de digestibilidade dos carboidratos totais.

no período em que esse estudo a forragem apresentava excelente estrutura comprovada pela relação folha:colmo encontrada $(1,32 \%)$, portanto os animais puderam pastejar quase que exclusivamente as folhas, que por serem mais nutritivas apresentam maior taxa de digestão quando comparado com as demais partes da planta. Como se tratava de material de qualidade, o aumento da TxBOC e do BOCDIA propiciaram maior consumo de um material que era de boa digestibilidade. Caso contrário, ocorreria uma limitação do consumo devido às limitações físicas impostas pela má qualidade da forragem.

Constatou-se correlação negativa $(p<0,05)$ entre o tempo por bocado (TemBOC) e o CDEE. O número de bocados por deglutição (NumBOC) apresentou correlação positiva com o CDPB. Explicado pela alta disponibilidade de folhas $(2516 \mathrm{~kg} / \mathrm{ha})$ e por ser este o componente mais nutritivo e mais palatável do pasto, há uma preferência do animal pelas lâminas foliares, portanto as decisões do animal pela procura de forragem estão baseadas, preferencialmente na busca por esse componente (Teixeira et al., 2010).

$\mathrm{O}$ número de bolos ruminados por dia (BOL/dia) apresentou correlação positiva $(\mathrm{p}<0,05)$ com todos os coeficientes de digestiblidade dos nutrientes estudados, exceto com o CDEE (tabela VIII). Conforme discutido anteriormente, quanto mais tempo o animal ruminar, melhor será o processo de redução de partículas dos alimentos ingeridos, e consequentemente, melhor também será o seu aproveitamento.

Observou-se correlação positiva $(\mathrm{p}<0,05)$ entre o número de mastigações merícicas por dia (MAS/dia) e o coeficiente de digestibilidade da MS, MO e CT. Como explicado anteriormente, quando os animais ingerem maiores teores de MS provenientes do pasto há necessidade de um maior tempo de ruminação devido a maior necessidade de processar a fibra, pois de acordo com Van Soest (1994), a atividade de mastigação tem um importante papel no consumo e digestão de forragens, influenciando a taxa de secreção salivar, solubilizando os nutrientes, quebrando e re- 
duzindo o tamanho das partículas e expondo os nutrientes, para a colonização e aumentando a taxa de passagem da digesta.

Correlações positivas foram observadas $(p<0,05)$ entre a eficiência de alimentação da matéria seca (EALMS) e da fibra em detergente neutro (EALFDN) com o coeficiente de digestibilidade dos nutrientes estudados (tabela IX). Com o fornecimento de suplemento proteico/energético, há melhoria da eficiência de alimentação da matéria seca e por consequência dos demais nutrientes. O aumento da eficiência de alimentação da FDN está diretamente relacionada ao consumo eficiente de forragem de qualidade, pois, esta disponibiliza maiores níveis de fibra na dieta total dos animais. O consumo desta forragemé eficiente devido não haver limitações na oferta.

Correlações positivas foram observadas $(p<0,05)$ entre a eficiência de ruminação da matéria seca (ERUMS) e da fibra em detergente neutro (ERUFDN). Segundo Macedo Júnior et al. (2010) e Berchielli et al.
(2011) a ingestão de MS está positivamente relacionada com a digestibilidade da FDN, portanto, com o fornecimento adicional de nutrientes via suplementação os animais se tornaram mais eficientes na alimentação da forragem disponível, graças a melhoria na digestibilidade da mesma, possível aumento da taxa de passagem e por consequência um maior consumo.

Podemos concluir, portanto que a digestibilidade dos nutrientes exerce influência direta sobre as expressões comportamentais apresentadas pelos animais estudados, principalmente no que diz respeito às atividades de ruminação. Os resultados discutidos no presente trabalho demonstram que são equivocados grande parte dos comentários feitos até então e que versavam contra a importância dos estudos de correlação. Espera-se no futuro com o aprofundamento de estudos desta natureza, a obtenção de respostas inerentes à digestão dos alimentos por meio do estudo das expressões comportamentais.

Tabela VIII. Coeficientes de correlação linear entre a digestibilidade dos nutrientes e os aspectos da ruminação do comportamento ingestivo de novilhos mestiços recebendo suplementação proteico/energética ou suplementação mineral em pastagens de Brachiaria brizantha 'Marandu' no periodo das águas. (Linear correlation coefficients between nutrient digestibility aspects of rumination and ingestive behavior of crossbred steers receiving protein / energy supplementation or mineral supplementation on Brachiaria brizantha 'Marandu' during rainy).

\begin{tabular}{lcccc}
\hline & BOL/dia & TEM/bolo & MAS/bolo & MAS/dia \\
\hline CDMS & 0,4925 & - & - & 0,3651 \\
CDMO & 0,4881 & - & - & 0,3650 \\
CDFDNcp & 0,5218 & - & - & - \\
CDPB & 0,3727 & - & - & - \\
CDEE & - & - & - & - \\
CDCNF & 0,4350 & - & - & 0,3624 \\
CDCT & 0,5269 & - & - & - \\
\hline
\end{tabular}

$\mathrm{BOL} / \mathrm{dia}=$ número de bolos ruminados por dia; TEM/bolo= tempo por bolo ruminado; $\mathrm{MAS} / \mathrm{bolo}=$ mastigações merícicas por bolo; MAS/dia= número de mastigações merícicas por dia; CDMS= coeficiente de digestibilidade da matéria seca; $\mathrm{CDMO}=$ coeficiente de digestibilidade da matéria orgânica; $C D F D N c p=$ coeficiente de digestibilidade da fibra em detergente neutro corrigido para cinzas e proteína; $C D P B=$ coeficiente de digestibilidade da proteína bruta; $\mathrm{CDEE}=$ coeficiente de digestibilidade do extrato etéreo; $\mathrm{CDCNF}=$ coeficiente de digestibilidade do carboidrato não fibroso; $\mathrm{CDCT}=$ coeficiente de digestibilidade dos carboidratos totais. 
Tabela IX. Correlações das eficiências de alimentação e ruminação com a digestibilidade dos nutrientes em novilhos de origem leiteira recebendo suplementação proteico/energética ou suplementação mineral em pastagens de Brachiaria brizantha 'Marandu' no periodo das águas. (Correlations efficiencies of eating and ruminating on the digestibility of nutrients in dairy steers receiving source protein / energy supplementation or mineral supplementation on Brachiaria brizantha 'Marandu' during rainy).

\begin{tabular}{lcccccccc}
\hline Variável & INGMS & INGFDN & EALMS & EALFDN & ERUMS & ERUFDN & RUGMS & RUGFDN \\
\hline CDMS & - & - & 0,5856 & 0,5073 & 0,6857 & 0,6316 & - & - \\
CDMO & - & - & 0,6086 & 0,5289 & 0,6813 & 0,6249 & - & - \\
CDFDNcp & - & - & 0,6641 & 0,6025 & 0,6392 & 0,5931 & - & - \\
CDPB & - & - & 0,5585 & 0,4476 & 0,6652 & 0,5842 & - & - \\
CDEE & - & - & 0,4469 & 0,3495 & 0,6111 & 0,5422 & - & - \\
CDCNF & - & - & 0,3933 & 0,3276 & 0,6131 & 0,5740 & - & - \\
CDCT & - & - & 0,6046 & 0,5450 & 0,6576 & 0,6169 & - & -
\end{tabular}

INGMS= ingestão em gramas de material seca; INGFDN= ingestão em gramas de fibra em detergente neutro; EALMS= eficiência de alimentação da matéria seca; $E A L F D N=$ eficiência de alimentação da fibra em detergente neutro; ERUMS= eficiência de ruminação da matéria seca; ERUFDN= eficiência de ruminação da fibra em detergente neutro; RUGMS= ruminação em gramas de matéria seca; RUGFDN= ruminação em gramas da fibra em detergente neutro; $\mathrm{CDMS}=$ coeficiente de digestibilidade da matéria seca; $\mathrm{CDMO}=$ coeficiente de digestibilidade da matéria orgânica; $C D F D N c p=$ coeficiente de digestibilidade da fibra em detergente neutro corrigido para cinzas e proteína; $C D P B=$ coeficiente de digestibilidade da proteína bruta; $\mathrm{CDEE}=$ coeficiente de digestibilidade do extrato etéreo; $\mathrm{CDCNF}=$ coeficiente de digestibilidade do carboidrato não fibroso; $\mathrm{CDCT}=$ coeficiente de digestibilidade dos carboidratos totais.

\section{BIBLIOGRAFIA}

AOAC. Association of Official Analytical Chemists. Official methods of analysis. 1990. 15 ed. Washington. $1018 \mathrm{pp}$.

Baggio, C.; Carvalho, P.C.F.; Silva, J.L.S.;Anghinoni, I.; Lopes, M.L.T. e Thurow, J. M. 2009. Padrões de deslocamento e captura de forragem por novilhos em pastagem de azevém-anual e aveia-preta manejada sob diferentes alturas em sistema de integração lavoura-pecuária. Rev Bras Zootecn, 38: 215-222.

Berchielli, T.T.; Pires, A.V. e Oliveira, S.G. 2011. Nutrição de ruminantes. $2^{\circ}$ edição. FUNEP-Fundação de Apoio a Pesquisa, Ensino e Extensão. Jaboticabal. $616 \mathrm{pp}$.

Burger, P.J.; Pereira, J.C.; Queiroz, A.C.; Silva, J.F.C. da; Valadares Filho, S.C.; Cecon, P.R. e Casali, A.D.P. 2000. Comportamento ingestivo de bezerros holandeses alimentados com dietas contendo diferentes níveis de concentrado. Rev Bras Zootecn, 29: 236-242.

Casali, A.O. 2006. Procedimentos metodológicos in situ na avaliação do teor de compostos indigestí- veis em alimentos e fezes de bovinos. Dissertação (Mestrado em Zootecnia). Universidade Federal de Viçosa. Viçosa. 47 pp.

Coelho da Silva, J.F. e Leão, M.I. 1979. Fundamentos de nutrição dos ruminantes. Livroceres Piracicaba. 380 pp.

Detmann E.; Souza, M.A.; Valadares Filho, S.C.; Queiroz, A.C.; Berchielli, T.T.; Saliba, E.O.S.; Cabral, L. da S.; Pina, D. dos S.; Ladeira, M.M. e Azevedo, J.A.G. 2012. Métodos para análise de alimentos - INCT - Ciência Animal. Instituto Nacional de Ciência Tecnologia de Ciência Animal. Cap. 15.

Hall, M.B. 2003. Challenges with non-fiber carbohydrate methods. J Animal Sci, 81: 3226-3232.

Hodgson, J. 1982. Ingestive behavior. Leaver, J.D. (Ed.) Herbage intake handbook. Brit. Grassland Soc. Hurley. p. 113.

Jamieson, W.S. e Hodgson, J. 1979. The effect of variation in sward characteristics upon the ingestive behavior and herbage intake of calves and 
lambs under continuous stocking management. Grass Forage Sci, 34: 273-281.

Johnson, A.D. 1978. Sample preparation and chemical analysis of vegetation. In: Manetje, L.T. (Ed.) Measurement of grassland vegetation and animal production. CommonwealthAgricultural Bureaux. Aberustwyth. Pp.: 96-102

Lazzarini, I.; Detmann, E.; Sampaio, C.B.; Paulino, M.F.; Valadares Filho, S.C.; Souza, M.A. e Oliveira, F.A. 2009. Dinâmicas de trânsito e degradação da fibra em detergente neutro em bovinos alimentados com forragem tropical de baixa qualidade e compostos nitrogenados. Arq Bras Med Vet Zoo, 61: 635-647.

Macedo Júnior, G.L.; Ferreira, M.I.C.; Borges, I.; Silva, V.B. da; Couto, J.R.L. e Cavalcanti, L.F.L. 2010. Consumo e digestibilidade aparente das frações fibrosas por ovelhas gestantes submetidas ou não à restrição nutricional. Rev Bras Saúde Prod Anim, 11: 179-192.

Mendonça, S.S.; Campos, J.M.S.; Valadares Filho, S.C.; Valadares, R.F.D.; Soares, C.A.; Lana, R. de P.; Queiroz, A.C.; Assis, A.J. e Pereira, M.L.A. 2004. Comportamento ingestivo de vacas leiteiras alimentadas com dietas à base de cana-de açúcar ou silagem de milho. Rev Bras Zootecn, 33: 723-728.

Mertens, D.R. 2002. Gravimetric determination of amylase-treated neutral detergent fiber in feeds with refluxing in beakers or crucibles: collaborative study. J AOAC Int, 85: 1217-1240.

NRC - National Research Council. 2001. Nutrient requirements of dairy cattle. 7.ed. NatAcad Press. Washington, D.C., $381 \mathrm{pp}$.

Rode, L.M.; Weakley, D.C. and Satter, L.D. 1985. Effect of forage amount and particle size in diets of lactating dairy cows on site of digestion and microbial synthesis. Can J Anim Sci, 65: 101-111.

Santana Júnior, H.A.; Silva, R.R.; Carvalho, G.G.P, Silva, F.F.; Mendes, F.B.L.; Abreu Filho, G.; Trindade Júnior, G.; Cardoso, E.O.; Barroso, D.S. e Pereira, M.M. 2012. Correlação entre digestibilidade e comportamento ingestivo de novilhas suplementadas a pasto. Arch Zootec, 61: 549-558.

Saliba, E.O.S.; Rodriguez, N.M. and Piló-Veloso, D. 2003. Purified lignina extraded from Eucalyptus grandis (PELI), used as na external marker in digestibility trials in various animal species. World Conference on Anim. Production. Porto Alegre, RS. WAAP/ALPA/SBZ/UFRGS.
Silva, R.R.; Silva, F.F.; Prado, I.N.; Carvalho, G.G.P.; Franco, I.L.; Almeida, V.S.; Cardoso, C.P. y Ribeiro, M.H.S. 2006. Comportamento ingestivo de bovinos. Aspectos metodológicos. Arch Zootec, 55: 293-296.

Silva, R.R.; Prado, I.N.; Carvalho, G.G.P, Silva, F.F.; Santana Júnior, H.A.; Souza, D.R. de; Dias, D.L.S.; Pereira, M.M.; Marques, J.A. e Paixão, M.L. 2010. Novilhos nelore suplementados em pastagens: Consumo, desempenho e digestibilidade. Arch Zootecn, 59: 549-560.

Sniffen, C.J.; O'Connor, J.D.; Van Soest; P.; Fox, D.G.; Rurrell, J.B. 1992. A net carbohydrate and protein system for evaluating cattle diets: II- Carbohydrate and protein availability. J Dairy Sci, 70: 3562-3577.

Souza, D.R.; Silva F.F.; Rocha Neto, A.L.; Silva, V.L. da; Dias, D.L.S.; Souza, D.D. de; Almeida, P.J.P. e Pondé, W.P.S.T.S. 2012 Suplementação proteica a pasto sob o consumo, digestibilidade e desempenho na terminação de novilhos Nelore na época das águas. Rev Bras Saúde Prod Anim,13: 1121-1132.

Teixeira, F.A.; Marques, J.A.; Silva, F.F. e Pires, A.J.V. 2010. Comportamento ingestivo e padrão de deslocamento de bovinos em pastagens tropicais. Arch Zootec, 59: 57-70.

Trevisan, N.B.; Quadros, F.L.F.; Coradini, A.F.S.; Bandinelli, D.G.; Martins, C.E.N.; Simões, L.F. C.; Maixner,A.R. ePires, D.R.F. 2004 . Comportamento ingestivo de novilhos de corte em pastagem de aveia preta e azevém com níveis distintos de folhas verdes. Rev Ciência Rural, 34: 1543-1548.

Valadares Filho, S.C.; Moraes, E.H.B.K. e Detmann, E. 2006. Perspectivas do uso de indicadores para estimar o consumo individual de bovinos alimentados em grupo. Reunião Anual da Sociedade Brasileira de Zootecnia, 44. João Pessoa. Anais Soc Bras Zootecn. João Pessoa.

Van Soest, P.J. 1994. Nutritional ecology of the ruminant. 2.ed. Comstock Publishing Associates. Ithaca. $476 \mathrm{pp}$.

Weiss, W.P. 1999. Energy prediction equations for ruminant feeds. Cornell Nutrition Conference for Feed Manufacturers. Ithaca. Proceedings... Cornell University. Ithaca. 61: 176-185. 